\title{
EDUARDO FROTA, NUNO RAMOS: PALAVRA E MODOS DE USO*
}

\author{
MANOEL RICARDO DE LIMA estabelece paralelos entre o \\ conceito de monumento derivado da literatura de Robert \\ Musil, obras em prosa de Nuno Ramos e trabalhos de \\ Eduardo Frota
}

Robert Musil, autor de Der Mann ohne Eigenschaften (O homem sem qualidades), escreve uma espécie de dicionário crítico nos relatos que compõem o pequeno volume intitulado Nachlass zu Lebzeiten (Obra póstuma publicada em vida). Um desses relatos, de uma parte do livro chamada de "Considerações inamistosas", chama-se "Monumentos". Musil arma um problema de perquirição em torno do termo e abre uma série de extensões ao sentido: numa delas diz categórico que ninguém os nota, porque "não há no mundo inteiro nada tão invisível quanto os monumentos." [1] Esta ideia de monumento, me parece, remete também a um modo de uso e operação da palavra em torno de uma história monumentalizada que insiste numa monopolização da memória, porque a palavra é também erguida para ser vista, para despertar a atenção a algo, em algo, com algo, a palavra é o que chama, é o que convida algo a existir. Completa Musil que os monumentos

\begin{abstract}
foram erguidos, sem dúvida, para ser vistos ou, mais categoricamente, para despertar a atenção; revestem-se simultaneamente de algo que vai de encontro à atenção, a qual, obediente, escorre por eles como gotas de água sobre uma camada de azeite, sem se deter um só instante.[2]
\end{abstract}

É possível pensar que a palavra assume um dizer, a forma de uma força, aquilo que a encarna e que ela encarna, exatamente porque se modula num movimento ambivalente entre o que desperta a atenção e o que vai de encontro à atenção, entre o que erige um monumento e o que, ao mesmo tempo, pode desmanchá-lo, lançá-lo ao chão e apagá-lo. O poeta/artista visual Nuno Ramos, por exemplo, que tem esticado o seu trabalho do suporte de um espaço na geometria escalonada da arquitetura de galerias e instituições até o suporte sofisticado que ainda é o

\footnotetext{
* outra versão deste ensaio foi publicada na revista poiesis, do programa de pós-graduação em ciência Da arte da universidade federal fluminense, uff - n. 18 - ano 12 - dezembro 2011.

1. MUSIL, Robert. O melro e outros escritos de obras póstumas publicadas em vida. Trad. Nicolino Simone Neto. São Paulo: Nova Alexandria, 1996, p. 48.

2. Id., ibid.
} 
livro[3], sem perder de vista que um trabalho é também o outro, que este outro é também um mesmo, procura indicar que toda obra de arte é feita de nosso horror, como sugere Michel Deguy, e que toda palavra é Dichtung: o dizer, um dizer, um ter a dizer, um dizer aquilo que resta etc. Assim, é possível pensar que os modos de uso da palavra podem ser tomados como vetores que saem do sentido espremido da representação para sugerirem-se ao mundo como um objeto, uma interdição, como "associações disjuntivas", uma "extensão da fenda" ou "intervenções extensivas" (estas expressões são do artista Eduardo Frota e dão título a algumas de suas exposições)[4], mas também sempre como peças de poder. No trabalho de Eduardo Frota, outro exemplo, a palavra não comparece senão nos títulos, que abrem por sua vez - articulações singulares, mas também ambivalentes e/ou redundantes, o que é interessantíssimo, ainda mais se pensarmos que o trabalho de Eduardo Frota se constitui em torno de uma linha da imaginação do corpo, para o corpo e com o corpo. Esta é a sua política. Uma linha que vem da tentativa de ler uma etnografia da origem de nossa cultura, quase nacional, mas tensionada também em direção ao poema moderno sem o verso, mas com o uso de uma ideia da linha. E aí tanto faz se com João Cabral de Melo Neto (a linha curta e irrespirável, a linha longa e irrespirável) ou se com Manuel Bandeira (a linha longa e aberta, a linha curta e aberta, quando a prosa não coincide mais com o romance, mas sim e também com o poema).

Esta oxigenação da forma, este gesto de levar a forma a sua exaustão ou de elaborar uma fratura no sentido por meio da própria fratura (como a leitura que Raúl Antelo faz da literatura de Oswald de Andrade, por exemplo), são apontamentos que provocam uma exasperação do sentido. Note-se que os três primeiros livros[5] de Nuno Ramos se intitulam com escavações ao diabo: Cujo (aquilo que não se pode dizer o nome), O pão do corvo (a comida para o pássaro preto, o delator, e muitas vezes o nome impróprio do urubu)[6] e $O$ (uma invocação, e também o círculo elíptico e santo, e se extremo também erótico, armado por Padre Vieira no Sermão de Nossa Senhora do Ó); ou seja, ao mesmo tempo, o não-sei-

3. Basta ver a primeira edição de Cujo (1993), o primeiro livro de Nuno Ramos, feito com papel bíblia, especial e transparente, a capa em Couché Reflex Matte, com 150 exemplares numerados e assinados por ele. O conceito e o procedimento da transparência denunciam um caráter fundamental desse livro como uma zona de contato em torno da palavra como superfície e interfície. Há, ainda, outra edição do mesmo livro pela Editora 34, mesmo ano, feita de forma mais simples e padrão, para ser comercializada e, obviamente, com o desaparecimento dessa questão.

4. Eduardo Frota tem usado esses títulos como um desdobramento do corpo desejoso e alucinatório que ele persegue para tensionar a história da arte e algumas questões em torno do pensamento da arte no Brasil; assim, repete insistentemente como se fossem termos de composição e os rearma outra vez como vertigem, sem parar, construindo assim séries numeradas de trabalhos para exposições diferentes. Como por exemplo a exposição realizada no ano 2000, no Torreão, em Porto Alegre, que se intitula "Espaço e Sentido/Intervenções Extensivas" que faz parte da série Intervenções Extensivas, ou a exposição intitulada "Intervenções em Trânsito", realizada no MAM, do Rio de Janeiro, em 2006, que faz parte da série homônima.

5. Optei por não incluir o quarto livro de Nuno Ramos, O mau vidraceiro (São Paulo: Globo, 2010), porque nesse momento o livro não me parece ainda articular os problemas que me interessam pensar aqui nesse texto.

6. Na 29a Bienal de São Paulo, Nuno Ramos expôs um trabalho intitulado Bandeira Branca com três urubus vivos e engaiolados junto a três enormes esculturas de areia preta aparentemente frágeis com caixas de som de onde se ouvia as canções "Bandeira Branca", "Boi da Cara Preta" e "Carcará". Este trabalho rendeu uma série de questionamentos quase absurdos e um corajoso e convicto texto de Nuno Ramos na Folha de São Paulo [Caderno Ilustríssima, 17/10/2010] em resposta aos abusos da palavra frágil contra o seu trabalho e seu projeto político em torno de um pensamento para a arte. 
que-diga, o não, o sem, o cão, aquilo que não sabemos, uns furos no saber etc. Ficamos diante de um trabalho que propõe um pensamento em torno da palavra que não pode ser dita, a palavra proibida, que é toda ela apenas invocação de uma lembrança solta e diabólica, mas também da palavra que é título, cabeçalho, lugar da atenção, exposição e deriva do sentido.

Seguindo, Musil ainda lembra que há monumentos vigorosos e outros que ainda são a expressão de um pensamento e de um sentimento vivos, mas que o ofício de grande parte dos monumentos comuns é, sem dúvida, o de invocar uma lembrança ou de chamar a atenção. Ou seja, Musil não capitula, porque para ele ao chamar a atenção o monumento se dá a ver na impressão de um sentimento piedoso, numa crença de que eles são de alguma forma necessários. E aí, completa, é que o monumento fracassa, que ele afugenta aquilo que deveria atrair:

Impossível dizer que não os percebemos; deveríamos dizer, isto sim, que nos passam despercebidos, que escapam aos nossos sentidos: é uma qualidade totalmente positiva, que tende para o ato de violência!

Ora, para isso há uma explicação possível, por certo. Tudo que é duradouro perde seu poder de impressionar. Tudo o que constitui as paredes de nossa vida ou, por assim dizer, os cenários de nossa consciência perde a capacidade de representar algum papel dentro dessa consciência. Ao cabo de poucas horas deixamos de ouvir o barulho incômodo e permanente. Os quadros pendurados nas paredes em poucos dias são absorvidos por elas; é muito raro que alguém pare diante deles para admirá-los. Livros, lidos pela metade e dispostos entre as magníficas fileiras de volumes da biblioteca, nunca mais voltarão a ser lidos até o final. De fato, às pessoas sensíveis basta a aquisição de um livro cujo início lhes agradou, e elas nunca mais voltarão a tê-los nas mãos.

$[\ldots]$

Quando temos as melhores intenções para com os monumentos, é inevitável que cheguemos à conclusão que eles, em contrariedade com a nossa natureza, nos apresentam uma reivindicação legítima cujo cumprimento só se dará em estabelecimentos muito especiais. Seria um crime se quiséssemos adaptar as placas de aviso para caminhões de uma forma tão discretamente monocromática como a dos monumentos. Até as locomotivas produzem sons estridentes e desconcertantes, e mesmo às caixas de correio damos uma cor atrativa. Numa palavra: os monumentos, assim como nós, deveriam se esforçar um pouco mais.[7]

7. MUSIL, Robert. O melro e outros escritos de obras póstumas publicadas em vida. Trad. Nicolino Simone Neto. São Paulo: Nova Alexandria, 1996, p. 49 e 50. 
A palavra, pois, se um monumento, comparece como um apontamento de nosso fracasso, de nossa falta de esforço com a linguagem - a linguagem é o lugar da atenção, disse Blanchot -, de nossa situação sempre desesperadora: quando a prosa cai onde e para onde cai a prosa, por exemplo. Porque é diante da palavra que nos postamos ao cruzar com os carretéis enormes ou com longos tubos furamundo e desangulados de Eduardo Frota, esta linha invisível de uma escultura depois do verso que constitui qualidades de intervenção desagregadoras, e não apenas expositivas, mas sugerindo outra "topologia simbólica do espaço expositivo" com "brechas, atravancamento, amontoado, distanciamentos, vazios, viscosidade, o escorregadio ou inclinação." [8] O que nos resta, nesse tempo de ínterim, de espera, sempre, é dizer o que resta. Ficamos entre o que se diz e o que se compreende do objeto, entre o que se diz e se escreve do objeto, quando o que se diz e o que se escreve e o que se compreende é o objeto que temos. Para Benjamin, isto seria a semelhança imaterial da linguagem. Raúl Antelo chama atenção que toda ideia da significação que procura armar um saber histórico efetivo vem primeiro como um vazio; diz ele que todo valor ao se construir como um quebra-cabeças de peças alheias numa lógica dispersiva inscreve-se na ordem do acaso.

Esta lógica dispersiva, inscrita no acaso, se não é um procedimento de trabalho, é ao menos o monturo das narrativas como um problema filosófico que Nuno Ramos procura em seus três primeiros livros. No primeiro deles, por exemplo, Cujo, todo composto de fragmentos de anotações dispersas e ao léu, numa compósita de linhas curtas e irrespiráveis, linhas longas e irrespiráveis, linhas curtas e abertas, linhas longas e abertas, quando a prosa não coincide mais com o romance, mas sim e também com o poema, como um poema, o pequeno fragmento inicial aponta para um ato, um gesto, um mover-se do corpo em direção ao vazio da atenção com a linguagem, quando sugere que

\footnotetext{
Pus todos juntos: água, alga, lama, numa poça vertical como uma escultura, costurada por seu próprio peso. Pedaços do mundo [palavras, principalmente palavras] refletiam-se ali e a cor dourada desses reflexos dava uma impressão intocada de realidade. O som horrível de uma serra saía de dentro da poça e completava o ritual, como uma promessa [pela qual eu esperava, atento] que fosse conhecimento e revelação. Foi então, como se suasse, que algumas gotas apareceram em sua superfície e escorreram, primeiro lentas e depois aos goles, numa asfixia movediça que trouxe o interior à superfície e desfez em pedaços a suspensão e a paralisia. E feita
}

8. HERKENHOFF, Paulo. “Texto crítico”, In FROTA, Eduardo. Catálogo, Intervenções extensivas X. Vila Velha: Museu da Vale do Rio Doce, 2006, p. 18. 


\begin{tabular}{ll|l}
\hline celeuma & número $1 \mid$ volume $1 \mid$ maio 2013 & dossiê \\
\hline
\end{tabular}

sujeira, aos meus pés, era um lamento do que eu tinha visto e perdido.[9]

São esses pedaços do mundo, de mundo e no mundo, as palavras, que - no trabalho de Nuno Ramos - aparecem numa fulguração de seu uso como a constituição de uma pele. Uma pele que é também transparência, quando o sentido escorre numa superfície sem fundo e infinita até tentar esmaecer atenuada numa interfície oscilante. Há uma precisão no trabalho: "Inventar uma pele para tudo", diz ele. Mas ao mesmo tempo, afirma: "Não consigo passar da pele”.[10] Esta sugestão de uma superfície do sentido e para o sentido, quando é o disforme que organiza tudo e pela borda - como, por exemplo, "criar um céu aberto", "a pele do coelho sem o coelho dentro", "enxugar os fósforos", "osso feito de carne" etc. -, se encontra com a tentativa de busca do tempo perdido moderno da nossa "fração correta de fracasso" e, principalmente, da tentativa de começar a invadir uma interfície, como um gesto político: "Comecei a arrancar a pele das coisas." [11] O que sobra depois disso é uma sucessão contraditória de acidentes monótonos e uma pergunta aflita: "Aflição diante das coisas que duram. Para quem elas duram?"[12] Robert Musil convida a que se repare na duração das coisas que encontramos pelo caminho, se pergunta qual o motivo de erguerem-se monumentos aos "grandes homens" se as coisas são como são, e refuta: "Parece um primor de maldade. Já que ninguém lhes pode mais prejudicar em vida, mergulham-nos num mar de esquecimento, com um monumento ao redor do pescoço." [13] Se a palavra-monumento é uma coisa que dura, e aflige e mata, a proposição de romper a sua superfície e encontrar-se com sua interfície - como está no trabalho de Nuno Ramos - é também, como indica Raúl Antelo, uma possibilidade para que se possa pensar a história como uma aceleração de leituras, e melhor: "ler o presente como se fosse passado, o contexto como se fosse texto, atentando, em todo caso, para aquilo que não foi observado: o tempo perdido [memória ou utopia].....[14]

Uma reinvenção do tempo perdido da palavra, assim, uma ficção da história a partir dos modos de uso da palavra, como uma persistência. Eduardo Frota, de outra maneira, já disse que seu trabalho "parte para um intraduzível em poucas ou muitas palavras nesse mundo de voo alto e baixo, fundo e raso da existência."

\footnotetext{
9. RAMOS, Nuno. Cujo. São Paulo: Editora 34, 1993, p. 9.

10. Ibidem, p. 19.

11. Ibidem, p. 29.

12. Ibidem, p. 31.

13. Ibidem, p. 51.

14. ANTELO, Raúl. Transgressão e modernidade. Ponta Grossa: UEPG, 2001, p. 95.
} 
A palavra, pouco ou muito, aparece no seu trabalho como algo que nomeia o inominável, porque estamos diante de uma forma extensa da própria forma, um descabimento, uma forma esticada, que redesenha a pulsão erótica. A forma, ali, é também uma tentativa de procurar sua própria nudez, uma escultura de formas vacilantes, que se desestabiliza por dentro, que insiste em devolver o erótico à esfera conjunta do sagrado e da morte, do sacrifício e do divino como só se constituísse numa "zona de lama preta" (a expressão é de Joaquim Cardozo) de uma experiência que parece sempre a-humana, além do humano, do fora. Nesse tempo agora, não só como uma vacilação ou oscilação de uma deriva do sentido ao não-sentido que a palavra toma e elabora, mas também uma devolução da pele, a ruga (Nuno Ramos), e uma devolução da tripa, a fenda (Eduardo Frota).

Ora, isso comparece também nos outros livros de Nuno Ramos. Em Ó, por exemplo, desde o índice num acompanhamento dos títulos com suas séries desvalidas em coisas como "Tocá-la, engordar e pássaros mortos”, "Galinhas, justiça", "Recobrimento, lama-mãe, urgência e repetição, cachorros sonham?”, "Epifania, provas, erotismo, corpo-sim, corpo-não" etc., até a intersecção de passagem impenetrável de um tema a outro por dentro das narrativas quando elas tentam seguir o movimento sugerido por seus títulos. Em O pão do corvo, noutro exemplo, há um caráter de silêncio, susto e pasmo entre a mudez e a fala da palavra. Como está na mais que bonita narrativa intitulada "Eu peço ao vento": a conversa deliberada entre um leão e uma leoa quando estão muito longe um do outro, como uma fala perdida e solta no tempo, em que não há escuta, mas entendimento a partir do silêncio, de uma ferida aberta e sangue. Há um pedido ao vento e ao vá (imperativo que se nomeia numa substantivação) que levem ao outro uma pequena fagulha amorosa de espera e compreensão da falência da ajuda e da morte. Com José Gil é possível chamar a isto de uma "zona de iminência da irrupção da palavra." [15] E isto pode ser pensado a partir do que ele propõe, que esta zona teria a ver com um costume egípcio entre a mudez da morte e a nova fala do outro mundo, quando num dos ritos de passagem se abria a boca e os olhos do morto. Diz ele que esta zona demarca a impregnação da imagem não designada ainda pela linguagem, a imagem sem nome, a imagem-nua. Como me parece está também no trabalho de Eduardo Frota e suas variantes de tentativas em nomear suas exposições a partir do quanto exaure da forma até deixá-las em estado de abandono, plenas de vacilação. Há algo do dizer que escapa por definição à palavra, nos lembra José Gil, "nem por isso uma imagem-nua deixa de querer absolutamente falar." [16]

15. GIL, José. Sem título - escritos sobre arte e artistas. Lisboa: Relógio D’água, 2005, p. 25.

16. GIL, José. Sem título - escritos sobre arte e artistas. Lisboa: Relógio D’água, 2005, p. 25. 
Parece que a palavra entre o pouco uso de Eduardo Frota e o muito uso de Nuno Ramos se estabelece aí, nesses trabalhos, numa zona de iminência como uma operação crítica, logo política, de seus modos de uso. Isto se imprime, por fim, seguindo Valère Novarina, um pensador de teatro, esta fúria em direção ao ver (théa), quando nos coloca espectadores ativos exatamente diante da palavra, mas como uma fala. Ele argumenta que todo real é falado, que é sobre a fala que repousa a matéria[17], que a fala é a pauta do tempo. Diz ele que nada é sem voz e que todo visível é falado porque nada é sem linguagem. Recupera o princípio de que é a palavra que chama as coisas, que ela nos avisa que as coisas faltam e que, assim, ao chamá-las mantêm juntos o seu ser e seu desaparecimento: "Nós levamos o mundo na nossa boca ao falar." [18] e "O mundo aparece de um desaparecimento; é ao nos faltar que o real está diante de nós. [...] Em si mesma, a matéria não é nada. Ela é apenas uma linguagem feita de coisas.”[19] Esta imposição do mundo como algo chamado pela palavra, da palavra como fala, amalgama-se à ruga e à fenda (mas não só) e sugere aos seus modos de uso - numa operação crítica em torno do não-sentido do sentido - um ver: quando dizer é ver, quando ver é o dito, quando ler é ver. Se do objeto à palavra como objeto, se dar palavra ao objeto e à sua objetualidade, se a palavra como presençaausente de si mesma e à "súbita densidade da vida".

MANOEL RICARDO DE LIMA é poeta, professor de literatura brasileira da Universidade Federal do Estado do Rio de Janeiro (UNIRIO). Publicou Embrulho (7 Letras) e Quando todos os acidentes acontecem (7 Letras) [poemas]; Falas Inacabadas - objetos e um poema com Elida Tessler (Tomo Editorial), Entre Percurso e Vanguarda - alguma poesia de Paulo Leminski (Annablume) e 55 Começos (Editora da Casa)[ensaios]; entre outros.

17. Carlos Drummond de Andrade faz essa passagem de uma forma muito interessante: no poema "Mãos Dadas", de seu terceiro livro, Sentimento do Mundo (1940), no final do poema aparecem os versos "O tempo é a minha matéria, o tempo presente, os homens presentes, / a vida presente." No seu livro intitulado A vida passada a limpo (1958), no poema "Nudez", ele escreve um verso que refaz o percurso da série tempo, homens e vida presentes, 20 anos depois: "Minha matéria é o nada". Além da trajetória insuspeita dos versos, a elaboração de uma linha mais tensa em direção a uma genealogia do esvaziamento do sentido.

18. NOVARINA, Valère. Diante da palavra.Trad. Angela Leite Lopes. Rio de Janeiro: 7Letras, 2009, p. 19.

19. Ibidem, p. 20 e 21. 